\title{
Morphometry of Hypoplastic Fetal Guinea Pig Lungs following Amniotic Fluid Leak
}

\author{
MARGARET H. COLLINS, ADRIEN C. MOESSINGER, JEROME KLEINERMAN, \\ L. STANLEY JAMES, AND WILLIAM A. BLANC
}

Departments of Pathology and Pediatrics, Columbia University, College of Physicians and Surgeons and Department of Pathology, Mt. Sinai School of Medicine New York, New York 10032

\begin{abstract}
Deficient quantity of amniotic fluid causes fetal guinea pig lung hypoplasia. Oligohydramnios that lasts only $\mathbf{5}$ days in early gestation is sufficient to reduce fetal lung growth significantly. We quantitated lung structural alterations at 50 days gestation (term is 67 days) of fetal guinea pigs whose amniotic fluid was drained on day 45 gestation. The study period spans the late canalicularearly saccular phases of guinea pig lung growth. Compared to littermate controls $(n=4)$, experimental fetuses $(n=$ $5)$ have reduced lung:body weight ratio $(2.81 \pm 0.16$ versus $3.21 \pm 0.20 \times 10^{-2}, p<0.01$ ), indicating lung hypoplasia. Lung volume is significantly decreased in the experimental fetuses $(1.17 \pm 0.15$ versus $1.34 \pm 0.07 \mathrm{ml}, p<0.05)$. The proportion of lung containing parenchyma (i.e. developing alveoli and alveolar ducts) is reduced following oligohydramnios $(0.83 \pm 0.04$ versus $0.90 \pm 0.02, p<0.025)$. The hypoplastic lungs contain fewer saccules (fetal "alveoli") $\left(46 \pm 20\right.$ versus $\left.69 \pm 23 \times 10^{6}, p<0.1\right)$ and the surface area that would be available for gas exchange is decreased (698 \pm 234 versus $\left.974 \pm 80 \mathrm{~cm}^{2}, p<0.05\right)$. Lung volume and volume proportion of parenchyma are reduced in the experimental lung and therefore diminished parenchymal elastic tissue is anticipated. However, the total length of parenchymal elastic tissue in the experimental lungs is decreased to a surprising degree and is little more than half the length in control lungs $(504 \pm 222$ versus $974 \pm$ $70 \mathrm{~m}, p<0.0025)$. Such marked reduction in total length suggests that factors other than smaller lung size have contributed to the decrease of elastic tissue in the experimental group. In fact, elastic tissue length per unit volume is significantly reduced $(509 \pm 189$ versus $809 \pm 115 \mathrm{~m} /$ $\left.\mathrm{cm}^{3}, p<0.025\right)$ indicating an absolute decrease in parenchymal elastic tissue in the hypoplastic lungs. These data show that even a brief period of oligohydramnios beginning in the canalicular phase of development significantly reduces and modifies fetal guinea pig lung growth. (Pediatr Res 20: 955-960, 1986)
\end{abstract}

\section{Abbreviation}

ISA, internal surface area

Lung hypoplasia is a disorder of pulmonary growth resulting in lungs that are disproportionately small relative to body size.

Received February 10, 1986; accepted May 20, 1986.

Address for correspondence and reprint requests Dr. M. H. Collins, M.D., Department of Pathology, Babies Hospital BHA-T12, 3959 Broadway, New York, NY 10032

This work is supported by NIH Grant HL-14218. M.H.C. was supported by a New York Lung Association Fellowship.
This condition is currently recognized in one of seven perinatal autopsies (1) and may be increasing in incidence (2).

The clinical manifestations are likely to be determined by the degree of compromised pulmonary growth and range from tachypnea to irreversible pulmonary failure (3). Postmortem, hypoplasia is defined as reduced ratio of lung weight to body weight (4) and decreased lung DNA content (5). Radial alveolar count is a morphometric measurement of acinar complexity; in hypoplastic lungs counts are either reduced (4) or within normal range $(6-9)$.

There are multiple etiologies of lung hypoplasia and they can be categorized into disorders of amniotic fluid volume (10-12), disorders that compromise thoracic space (13-17), and disorders of the neuromuscular system $(6,18-21)$.

Premature and prolonged rupture of fetal membranes with continuous leakage of amniotic fluid causes oligohydramnios and lung hypoplasia. The time of onset and the duration of oligohydramnios both influence lung growth. The incidence of fetal lung hypoplasia is greater following rupture of membranes early (prior to $26 \mathrm{wk}$ ) compared to late in gestation (22). Prolonged duration of oligohydramnios is associated with both greater incidence (22) and severity of pulmonary growth reduction (3) but lung hypoplasia has been diagnosed following oligohydramnios lasting less than 3 wk (i.e. less than $7.5 \%$ of gestation $(3,22)$. Morphometric studies of lungs that are hypoplastic because of amniotic fluid leak have not been reported; in cases of renal agenesis and oligohydramnios, bronchi are reduced in number and alveoli are reduced in number and size (9).

Over the last several years, we have developed a guinea pig model of fetal lung hypoplasia associated with oligohydramnios due to ruptured membranes (23). Our data show that in the guinea pig, as in the human, both early onset and prolonged duration influence the incidence and severity of fetal lung hypoplasia (24). Recently, Hislop et al. (25) reported the adverse effects of amniocentesis on fetal lung development in Macaca fascicularis; amniotic fluid, varying in amount from none to total volume, was withdrawn and the pulmonary sequelae were analyzed at term, 2 or more months following amniocentesis. Our study differs because we have induced complete oligohydramnios and we have examined lungs shortly after the onset of oligohydramnios. We know from our previous work that a brief period of oligohydramnios in the late canalicular-early saccular phases of lung development significantly reduces guinea pig lung growth $(0.1307$ versus $0.1728 \mathrm{mg}$ DNA/g fetal weight, $n=6, p$ $=0.005$ ) (24). We now report the morphometric quantitation of lung structure in guinea pigs examined on gestational day 50 , at the end of only 5 days of oligohydramnios.

\section{MATERIALS AND METHODS}

Animal preparation. Pregnant guinea pigs (Cavia porcellus) were obtained 30 days after mating from Camm-Hartley Research Institute, Wayne, NJ. Pregnant animals were individually 
caged and fed Guinea Pig Chow no: 5025 (Ralston Purina Co., St. Louis, MO) and water ad libitum.

On day 45 gestation, a midline laparotomy was performed on pregnant animals under Ketamine and acepromazine anesthesia. The uterine horns were inspected and the number of fetuses determined. Each guinea pig fetus has its own placenta and amnion. To obtain experimental fetuses a $0.5 \mathrm{~cm}$ incision was made in the uterine wall and the fetal membranes of a single fetus were pulled and torn with a forceps, care being taken not to injure the vitelline vessels. All amniotic fluid was drained through the uterine incision. Untouched littermates, i.e. fetuses with intact membranes, served as controls. The abdominal incision was closed and dressed and mothers returned to their cages and allowed to recover from anesthesia. Preoperative daily care was resumed. The surgical procedure is described in more detail in Reference 24.

Fetal delivery and preparation. On day 50, under anesthesia, the laparotomy incision was reopened and fetuses were delivered following cessation of fetal movement. All amniotic sacs were examined for the presence of amniotic fluid and the volume was measured.

The fetuses were blotted dry and body weights were measured to $0.1 \mathrm{mg}$ on a Mettler balance. The fetal abdomen was opened through a midline abdominal incision, the diaphragm pierced, the sternum removed, and the heart and thymus dissected away. The lungs and tracheas were removed en bloc and weighed to $0.1 \mathrm{mg}$ on a Mettler balance. Tracheas were cannulated using 30 gauge Teflon TFE microbore tubing (Cole-Parmer Instrument Co., Chicago, IL) or PE-50 tubing (Clay Adams, Parsippany, $\mathrm{NJ}$ ). All control and experimental lungs were inflated at $20 \mathrm{~cm}$ water pressure with Ito-Karnovsky's fixative (26) for $24 \mathrm{~h}$. Leakage was determined by fall in the level of the fluid pressure column used to inflate the lungs. Only lungs that did not leak were used for morphometric study; all lungs were used for histologic examination.

Lung volume measurement. Lung volume was determined using an apparatus designed by one of us (JK). The volume of saline displaced by the lungs from a small chamber was measured using a capillary tube attached at one end to the chamber and at the other to a Hamilton syringe having $0.1 \mathrm{ml}$ graduations; a micrometer caliper attached to the middle of the capillary measured volume at $0.0008 \mathrm{ml}$ increments. Reported lung volume values were based on two measurements of saline displacement and these values did not differ from each other by more than \pm $1.5 \%$. The length and width of the fixed, inflated lungs were measured after lung volumes were determined.

Histology preparation. The lungs were processed for histology by progressive dehydration and embedment in paraffin. A $5 \mu \mathrm{m}$ full-face midcoronal section of all lungs was stained with hematoxylin and eosin, and an adjacent section was stained with resorcin-fuchsin (27) for elastic tissue.

Morphometry. Detailed morphometry was performed by light microscopy on at least one experimental and one control lung from each litter. Morphometric measurements were made as described by Dunnill (28) and for elastic tissue length the method of Niewoehner and Kleinerman (29) was used.

Two eyepiece graticules were utilized. One graticule consisted of a grid formed by 10 horizontal and 10 vertical lines intersecting each other at right angles. The other graticule contained a crosshair image formed by a single horizontal and vertical line intersecting at right angles.

Morphometric parameters measured from the slides were volume density of parenchyma and saccules, saccule number per unit area, and elastic tissue length per unit area.

Volume densities. Volume density is the fraction of the total volume of an organ occupied by a component. The lung is divided into two components, parenchyma and nonparenchyma. Parenchyma is the compartment of the lung distal to bronchioles that contains airspace and airspace wall tissue; parenchyma is the lung compartment in which gas exchange occurs. Nonpar- enchyma is the lung compartment containing structures through which gas exchange does not occur and consists of bronchi, bronchioles, large blood vessels, etc.

Volume densities were measured by point counting; the corners of the squares in the grid graticule were used as points; 100 points of the test grid were counted per field at $100 \times$ magnification; every fifth field was counted in all lungs except one experimental lung in which every other field was counted; an average of 25 fields/lung were counted in experimental lungs and 24 fields/lung in control lungs.

Saccular number. The potential gas-exchanging airspaces in fetal and newborn lungs differ morphologically from adult alveoli and are referred to as saccules. Saccules were defined as the airspaces distal to bronchioles having at least three walls.

The grid graticule was also used to count saccules. Saccules were counted in the area $\left(0.053 \mathrm{~mm}^{2}\right)$ contained within the grid at $430 \times$ magnification and included saccules intercepted by the top and left margins of the grid. Saccules in every other field were counted giving an average of 82 fields/lung in the experimental lungs and an average of 70 fields/lung in the control lungs.

Saccular number per unit volume was calculated using the formula $\mathrm{N}=\mathrm{n}^{3 / 2} / \mathrm{B} \sqrt{\mathrm{p}}$ where $\mathrm{n}=$ number saccules/unit area, $\mathrm{B}$ $=$ shape constant (1.5), $\mathrm{p}=$ volume density of saccular air. The total number of saccules was obtained by multiplying saccular number/unit volume by the product of total lung volume and volume density of parenchyma.

$I S A$. ISA is that area of the lung that is available for gasexchange; it is the collective surface area of all saccules.

ISA was derived by the formula: ISA $=\mathrm{NK}(\gamma \mathrm{V} / \mathrm{N})^{2 / 3}$ where $\mathrm{N}=$ total number of saccules, $\mathrm{K}=$ shape constant (4.8), $\gamma=$ volume density of parenchyma. The values of the shape constants $\mathrm{B}$ and $\mathrm{K}$ used in this study are those that have been derived for studies of adult human alveoli because the values for guinea pigs are not known.

Elastic tissue length. Elastic tissue fibers were stained with resorcin-fuchsin and appeared as discrete dark lines in tissue sections. Fibers were identified in each field by focusing up and down through the plane of the section. Most fibers appeared isolated; when bundles were encountered, each fiber was counted as one intercept. Only elastic tissue fibers in the parenchyma were counted; fibers in walls of bronchi, bronchioles, and blood vessels and in the pleura were excluded.

The number of intercepts made by a linear probe on elastic tissue fibers was counted in a horizontal plane passing from the base to the apex of the right and left lungs at $430 \times$ (average of 134 fields/lung in the experimental group; average of 137 fields/ lung in the control group). The number of intercepts divided by the area of the histologic section yielded the length of elastic tissue/unit area and this was multiplied by 2 to yield length/unit volume. Total length of parenchymal elastic tissue is equal to the length per unit volume multiplied by the product of lung volume and volume density of parenchyma.

Shrinkage factor. The area of the larger histologic section was measured, compared to the measurements of the fixed, inflated lung, and shrinkage factor for conversion of area of processed to fixed tissue was determined for each lung. This constant was applied to the saccular number $/ \mathrm{mm}^{2}$ and elastic tissue length/ $\mathrm{cm}^{2}$ measurements and averaged 1.5 for the experimental group and 1.7 for lungs in the control group. The greater shrinkage of control lungs contributed to the fact that for most measurements a slightly lower number of fields were available for counting compared to the experimental lungs.

Statistical analysis. Student's $t$ test was performed for statistical analysis and $p$ value less than 0.05 was considered significant.

Comparison to fetuses of undisturbed gestations. As part of a larger study of normal fetal guinea pig lung growth (30), fetuses from undisturbed gestations were delivered by cesarean section under Ketamine and acepromazine anesthesia at 45 and 50 days gestation. The lungs were processed in a manner identical to that 
described above for the lungs used in this study. These data were used to evaluate the impact of the stress of laparotomy and anesthesia on littermate control lung growth.

\section{RESULTS}

Body and lung weights, lung volumes, and morphometric data are presented in Table 1.

The average amniotic fluid volume for the controls was 3.4 $\mathrm{ml}$; this is consistent with previous measurements at this gestational age (31). Amniotic sacs of experimental fetuses did not contain fluid.

Body weights of the experimental fetuses are equal to those of the control fetuses. Lung weights in the experimental group are reduced compared to the control group, but the difference is not statistically significant. However, the ratio of lung weight to body weight is significantly decreased in the experimental fetuses, indicating lung hypoplasia.

The volumes of the hypoplastic lungs are significantly reduced and the ratio of lung volume to body weight is also less than for the control group.

Morphometry. The total number of saccules in the experimental lungs is only $67 \%$ of the total number in the control lungs; this reduction is not statistically significant because of the large standard deviation in each group.

ISA is markedly reduced in the experimental lungs. ISA is determined by lung volume, the total number of saccules, and the proportion of lung occupied by saccular airspace. Although the total number of saccules is not statistically reduced in the experimental group, total lung volume and volume density of parenchyma are statistically less and these reductions account for the significant diminution of ISA.

Volume density measurement of parenchyma shows that the architecture of the hypoplastic lungs differs from normal: the volume proportion of the experimental lungs devoted to saccular air and interstitial tissue is significantly reduced compared to the proportion in littermate control lungs. Therefore, the fraction of total lung volume occupied by nonparenchyma is greater in the hypoplastic than in control lungs.

Average saccular volume, volume density of saccular air, and of saccular air to parenchyma are indicators of saccular size. All of these show a slight decrease in the size of the airspaces in the experimental lungs. The SDs of these values in both groups are fairly large, indicating variability of saccular size in both experimental and control lungs.

The most striking abnormality in the experimental lungs is the reduced quantity of elastic tissue; the total length is reduced to nearly half the value in the control lungs. The reduction is not due solely to smaller size because the elastic tissue length per $\mathrm{cm}^{3}$ is also significantly diminished, indicating an absolute decrease of elastic tissue in the experimental lungs.

Morphology. Normal fetal guinea pig lung development is heterogeneous; foci of less mature areas are found in lungs in the canalicular and saccular growth phases (30). The less mature areas are recognized by higher epithelium, smaller and fewer airspaces, and less elastic tissue compared to the norm for the gestational age. Two of five experimental and two of four control lungs in this study contained less mature areas and counts from these areas were included in the counts made of all four lungs. These observations support the concept that guinea pig fetal lung development is heterogeneous and suggest that this heterogeneity is not accentuated by oligohydramnios. The concept of developmental inhomogeneity needs further work.

Experimental and littermate control lungs have morphologic characteristics compatible with 50 days gestational age. In both groups, interstitial vessels are abundant and there are capillaries abutting the airspaces sometimes without visible epithelial covering. However, the overall architecture of the experimental lungs appears simpler than the controls, i.e. the number of bronchial branches appear to be fewer and the contours of the airspaces are less scalloped (Fig. 1). The bronchioles appear closer to the pleura in the experimental lungs, indicating a reduction in the amount of parenchyma. Generally saccular epithelium is higher in the experimental lungs. Elastic tissue fibers appear reduced in the hypoplastic lungs (Fig. 2).

\section{DISCUSSION}

A short period of oligohydramnios during the late canalicularearly saccular phases of lung development causes fetal guinea pig lung hypoplasia. The lungs exhibit a disproportionate reduction in lung parenchyma, decreased number of airspaces, reduced surface area available for gas exchange, and diminished length of parenchymal elastic tissue.

Table 1. Lung and body wt, lung volumes, and morphometric data

\begin{tabular}{|c|c|c|c|c|c|c|}
\hline & \multirow[b]{2}{*}{ Control } & \multirow[b]{2}{*}{ Experimental } & \multirow{2}{*}{$\begin{array}{l}\% \text { Control } \\
\text { value }\end{array}$} & \multirow[b]{2}{*}{$p$} & \multicolumn{2}{|c|}{ Undisturbed } \\
\hline & & & & & 45 Days & 50 Days \\
\hline No. of litters & 3 & 3 & & & 2 & 1 \\
\hline No. of fetuses & 4 & 5 & & & 3 & 2 \\
\hline Body wt (g) & $35.73 \pm 3.54^{*}$ & $36.52 \pm 2.82$ & $102 \%$ & $<0.4$ & $24 \pm 7$ & $41 \pm 3$ \\
\hline Lung wt $(\mathrm{g})$ & $1.15 \pm 0.13$ & $1.02 \pm 0.10$ & $89 \%$ & $<0.1$ & NA $\dagger$ & $1.38 \pm 0.01$ \\
\hline Lung wt: body wt $\left(\times 10^{-2}\right)$ & $3.21 \pm 0.20$ & $2.81 \pm 0.16$ & $88 \%$ & $<0.01$ & NA & $3.36 \pm 0.25$ \\
\hline Lung volume $(\mathrm{ml})$ & $1.34 \pm 0.07$ & $1.17 \pm 0.15$ & $87 \%$ & $<0.05$ & $0.93 \pm 0.36$ & $1.72 \pm 0.09$ \\
\hline Lung volume: body wt $\left(\times 10^{-2}\right)$ & $3.77 \pm 0.27$ & $3.19 \pm 0.26$ & $85 \%$ & $<0.01$ & $3.79 \pm 0.53$ & $4.19 \pm 0.07$ \\
\hline Total no. saccules $\left(\times 10^{6}\right)$ & $69 \pm 23$ & $46 \pm 20$ & $67 \%$ & $<0.1$ & $32 \pm 20$ & $70 \pm 32$ \\
\hline No. saccules $/ \mathrm{mm}^{2}$ & $1264 \pm 155$ & $1077 \pm 204$ & $85 \%$ & $<0.1$ & $762 \pm 278$ & $1017 \pm 204$ \\
\hline No. saccules $/ \mathrm{cm}^{3}\left(\times 10^{6}\right)$ & $57 \pm 17$ & $46 \pm 13$ & $81 \%$ & $<0.2$ & $36 \pm 14$ & $45 \pm 19$ \\
\hline $\begin{array}{l}\text { Average saccular volume (ml } \\
\times\left(0^{-9}\right)\end{array}$ & $6.25 \pm 4.08$ & $6.14 \pm 2.28$ & $98 \%$ & $<0.5$ & $4.17 \pm 0.51$ & $6.20 \pm 3.96$ \\
\hline Internal surface area $\left(\mathrm{cm}^{2}\right)$ & $974 \pm 80$ & $698 \pm 234$ & $72 \%$ & $<0.05$ & $392 \pm 259$ & $998 \pm 8$ \\
\hline Volume density parenchyma & $0.90 \pm 0.02$ & $0.83 \pm 0.04$ & $92 \%$ & $<0.025$ & $0.83 \pm 0.07$ & $0.89 \pm 0.01$ \\
\hline Volume density saccular air & $0.31 \pm 0.09$ & $0.27 \pm 0.07$ & $87 \%$ & $<0.3$ & $0.15 \pm 0.06$ & $0.25 \pm 0.06$ \\
\hline $\begin{array}{l}\text { Volume density saccular air in } \\
\text { parenchyma }\end{array}$ & $0.34 \pm 0.10$ & $0.32 \pm 0.08$ & $94 \%$ & $<0.5$ & $0.18 \pm 0.05$ & $0.28 \pm 0.06$ \\
\hline Elastic tissue length $\left(\mathrm{m} / \mathrm{cm}^{3}\right)$ & $809 \pm 115$ & $509 \pm 189$ & $63 \%$ & $<0.025$ & $233 \pm 166$ & $348 \pm 6$ \\
\hline $\begin{array}{l}\text { Total length of elastic tissue } \\
\text { (m) }\end{array}$ & $974 \pm 70$ & $504 \pm 222$ & $52 \%$ & $<0.0025$ & $223 \pm 192$ & $535 \pm 12$ \\
\hline
\end{tabular}

\footnotetext{
* Mean \pm 1 SD.
}

$\dagger$ Not assessed. 


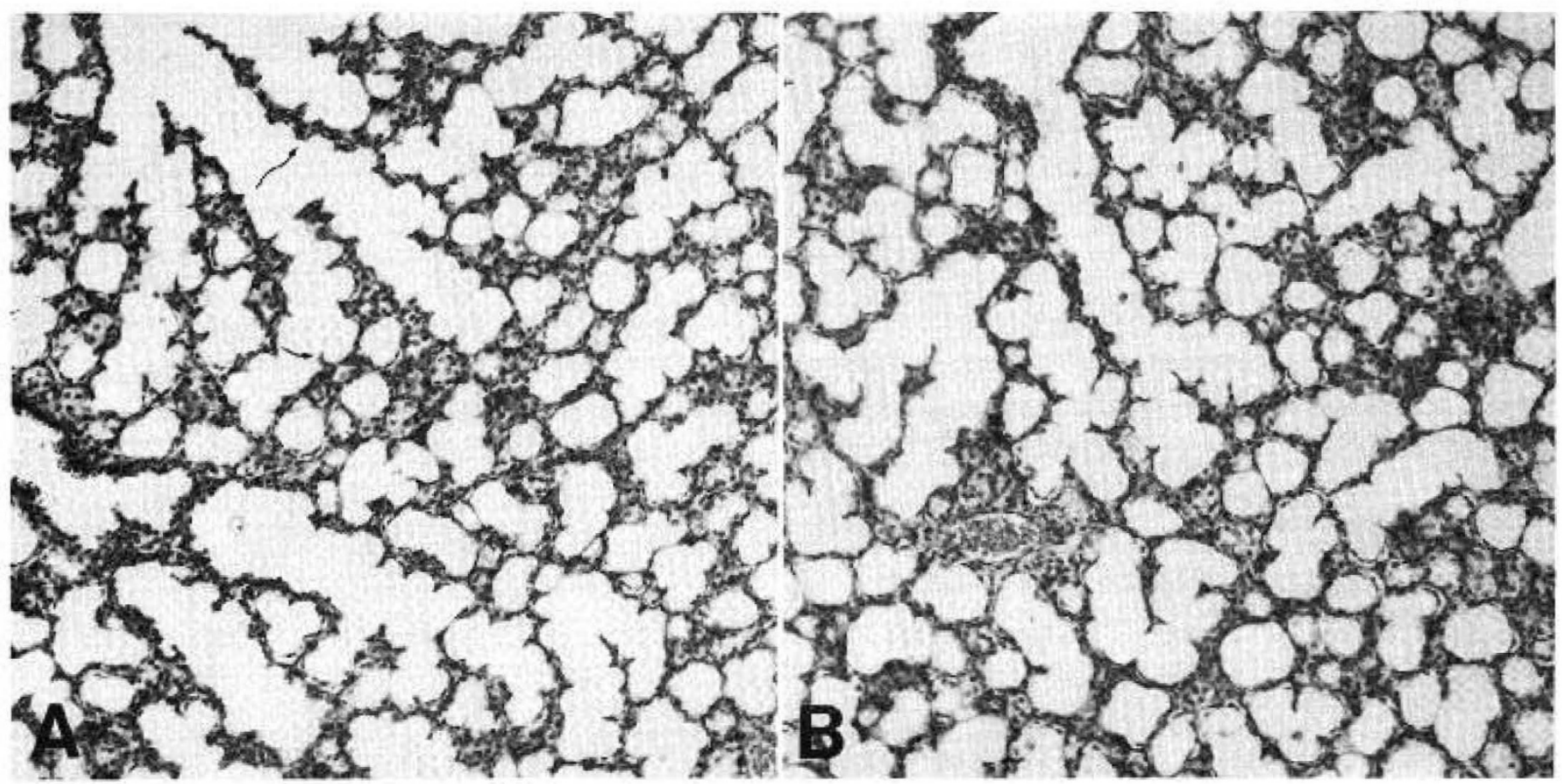

Fig. 1. Experimental and littermate control lungs on day 50. There appear to be more distal airway branches in the control $(A)$ compared to experimental $(B)$ lungs. In addition, the branches in the experimental lungs appear simpler than those of the controls, which contain larger numbers of septae (arrows). (Hematoxylin and eosin, $\times 150$.)

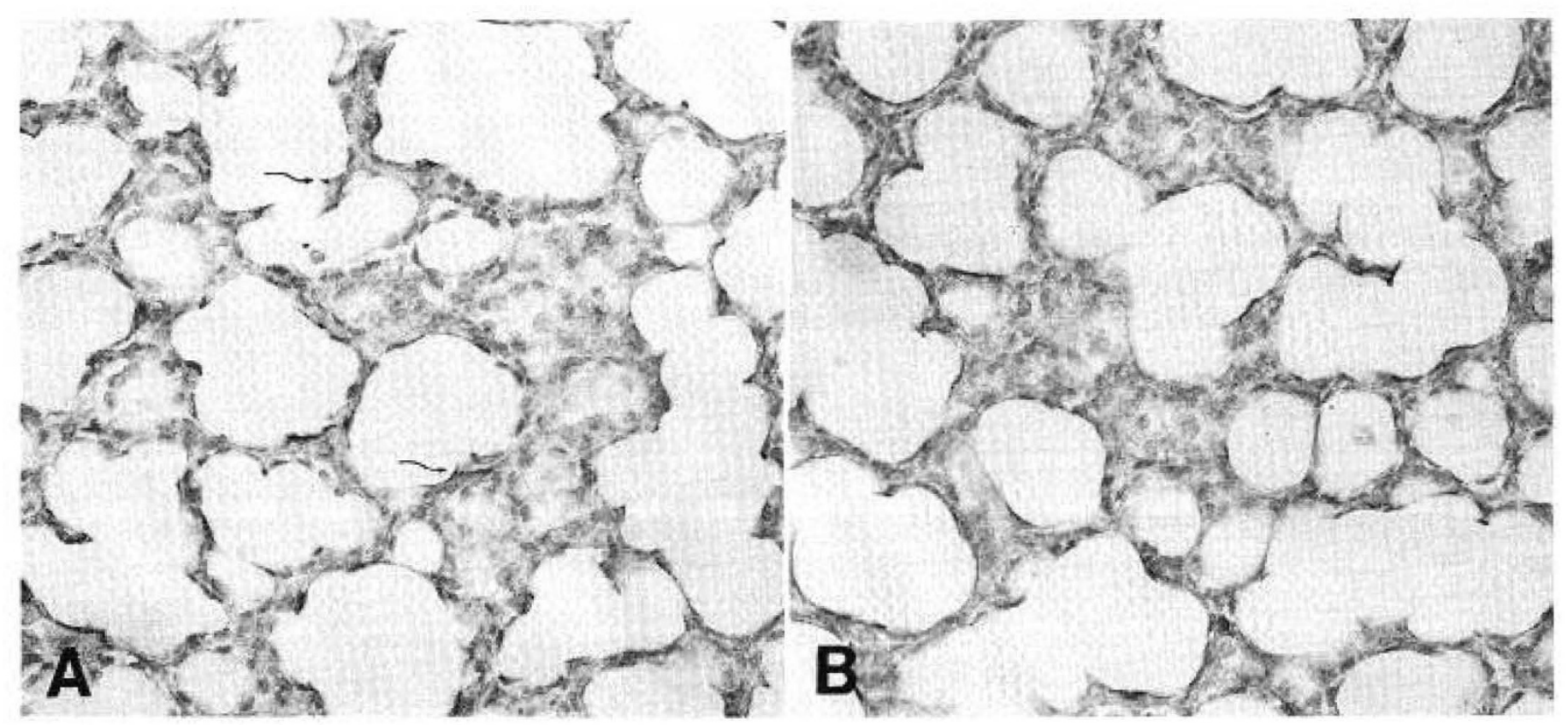

Fig. 2. Parenchymal elastic tissue. There appears to be more elastic tissue (darkly staining fibers at arrows in $A$ ) in the control than in the experimental lung $(B)$. (Resorcin-fuchsin, $\times 375$.)

The shape constants we have used for saccules are those used for adult alveoli. The purpose of this study is to compare the experimental and control groups. The shape of the developing alveolus may differ from the shape of the adult alveolus. Applying values for shape constants different from those used in adult lungs would change the absolute values in each group, but to the same degree; the ability to discriminate differences between the groups would not be enhanced. The shape of the developing alveolus in the experimental lungs may differ from the shape in the control lungs. However, the differences would have to be quite marked to significantly affect the values for saccular number and the shape of the saccules does not appear appreciably different in our sections.

We have studied the morphometry of guinea pig fetal lungs developing during undisturbed gestations (30), and the data from fetuses at 45 and 50 days gestation are presented in Table 1. 
Comparisons of some of the results from each study underscores the deleterious effect of oligohydramnios on lung growth. The lung:body weight ratio of experimental fetuses in this study is almost 2 SDs below that of normals at 50 days, but the ratio for littermate controls in this study is comparable to normals. Total lung volume of the controls is closer to the value previously measured at 50 days than is the value for experimentals.

The volume density data from our study of normal fetuses show that a parenchymal growth spurt occurs between 45 and 50 days; proportionately more of the lung is occupied by parenchyma on day 50 . This growth was severely impaired in the experimental animals; it is striking that the volume density of parenchyma is the same for the experimental fetuses at 50 days as it is for normal fetuses at 45 days, i.e. the time that oligohydramnios was created. The overall architecture of the hypoplastic lungs is abnormal, since proportionately more of the lung is devoted to nonparenchyma than in the normal lung.

ISA normally increases about 2.5 -fold between 45 and 50 days gestation. ISA in the hypoplastic lungs is less than twice that of normal fetuses at 45 days while ISA in the littermate control group is comparable to that at 50 days.

In normal fetuses, the increase in ISA during the late canalicular phase is due to both saccular proliferation and expansion. Total saccular number should more than double between 45 and 50 days; the number of saccules in our experimental fetuses is less than $50 \%$ greater than that of normals at 45 days, but the number in littermate controls is comparable to that of normals at 50 days. The magnitude of saccular proliferation that should occur between 45 and 50 days has been diminished by oligohydramnios. Average saccular volume increases between 45 and 50 days. Average saccular volume in littermate control lungs is comparable to that in normal fetuses at 50 days and only slightly less in hypoplastic lungs. The saccular expansion that should occur in the late canalicular phase has been minimally inhibited by oligohydramnios. Reduced ISA is, therefore, due primarily to reduction of saccular proliferation.

The data from this experiment indicate that elastic tissue has not proliferated to the expected degree in the hypoplastic lungs. In fetuses from undisturbed gestations, total length of parenchymal elastic tissue more than doubles between 45 and 50 days. The values of elastic tissue length obtained in the lungs in this study differ from the values obtained in the lungs of fetuses from undisturbed gestations. The values reported herein are less than those of three fetuses from two litters at 55 days $(1371 \pm 285$ $\mathrm{m})$, but equal to or greater than those previously measured at 50 days; the most reasonable explanation at this time is to attribute this finding to wide natural interlitter variation in elastic tissue growth.

Elastic tissue appears to play a critical role in alveolar development. One way alveoli are formed is through outgrowths of interstitial tissue from airspace walls. The outgrowths subdivide preexisting airspaces and are known as septal crests. In several studies $(32,33)$, including our own, it has been noted that septal crests almost always contain elastic tissue fibers. There is a strong correlation between the increase in saccular number and the increase in parenchymal elastic tissue length during normal guinea pig lung development (30). It is not yet known if septal crests induce elastic tissue development or if elastic tissue development is an inciting factor for crest formation. The intimate association between alveolar formation and elastic tissue growth is emphasized by the concomitant reduction of those parameters found in the hypoplastic lungs in our study.,

In the hypoplastic lungs of infants who have experienced oligohydramnios elastic tissue appears reduced (1) but this change has not been quantitated morphometrically. The most marked quantitative difference between experimental and control lungs in our study is profound reduction in parenchymal elastic tissue length. However, our data do not show that oligohydramnios has a specific effect on elastic tissue growth and development. Elastic tissue begins to appear in the parenchyma of the fetal guinea pig lung around day 45 gestation (30). Inducing oligohydramnios at a critical period in elastic tissue development at least partially explains the pronounced reduction in fiber length we are reporting. In addition, parenchymal elastic tissue is reduced in another model of fetal lung hypoplasia, that which is associated with maternal smoking during pregnancy (34), showing that oligohydramnios is not the only insult that affects elastic tissue growth. In the smoking model, saccular number and elastic tissue length are both significantly reduced, consistent with a close relationship between the growth of both. Since we used rats in our smoking model, we may conclude that diminution of parenchymal elastic tissue during abnormal lung growth is not peculiar to guinea pigs.

Morphometric studies of the lungs of human infants following amniotic fluid leaks have not been reported and there are few animal models. Fetal sheep examined $3 \mathrm{wk}$ after the onset of oligohydramnios during the canalicular phase of lung development have characteristics similar to those of guinea pigs in this study, i.e. decreased lung:body weight ratio, reduced lung volume, decreased lung DNA, decreased number of alveoli, reduced internal surface area, and diminished parenchymal elastic tissue (35).

In their study of the effect of amniocentesis on monkey lung development, Hislop et al. (25) did not report lung:body weight ratio. Total lung volume at term was reduced following amniocentesis at a time corresponding to the late pseudoglandularearly canalicular phase of human lung development, but not following amniocentesis in the late canalicular-early saccular phase of lung development. Lung volumes were significantly reduced following oligohydramnios during this time period in our study. We examined fetal lungs 5 days after intervention whereas Hislop et al. (25) examined the lungs after a considerably longer period of time and this may account for the difference. Also, our work examines the effect of oligohydramnios on lung development. Hislop et al. (25) do not state if the magnitude of their changes is greater after oligohydramnios as opposed to amniocentesis without fluid drainage. Respiratory bronchioles were decreased in number and size in monkey lungs following amniocentesis. We have not yet measured respiratory bronchioles; our study of normal guinea pig lung development showed that respiratory bronchioles are forming around day 50 so that a reduction might be anticipated following the onset of oligohydramnios on day 45 . Total alveolar number is significantly reduced in fetal monkeys following amniocentesis. In contrast to our finding, alveolar size is increased; this may be due to the use of different species or to the longer interval between intervention and examination in the study of Hislop et al. (25).

The importance of amniotic fluid volume for normal lung growth is illustrated by the fact that obstructing the fetal rabbit bladder to create oligohydramnios significantly decreases lung:body weight ratio, but subsequently restoring amniotic fluid volume to normal increases lung:body weight ratio to normal range (36). The precise role of amniotic fluid in the process of normal lung growth is not known, but there are several hypotheses relating normal fluid volume to normal lung growth. Fetal breathing movements could be altered during oligohydramnios in ways that deprive the growing lung of normal intermittent distending forces (37). Drainage of fetal lung fluid is known to cause sheep lung hypoplasia (38); the normal pressure differential, known to exist in sheep (39), between the upper airway and the amniotic cavity may become accentuated during oligohydramnios to favor egress of fetal lung fluid (35). If this were true, then smaller airway size might be a consequence; our data show only a minimal reduction in saccular volume. Increased outflow of lung fluid as a consequence of fetal compression by uterine walls has also been proposed as a factor leading to poor lung growth associated with oligohydramnios $(1,40)$.

Our data support the conclusion that oligohydramnios in the 
fetal guinea pig for a period of time no greater than $7-8 \%$ of gestation can cause lung hypoplasia with attendant pulmonary structural alterations. When this occurs during the canalicular phase of fetal lung development, the effects on growth, especially that of elastic tissue, may be particularly prominent.

\section{REFERENCES}

1. Wigglesworth JS, Desai R 1982 Is fetal respiratory function a major determinant of perinatal survival? Lancet 1:264-267

2. Moessinger AC, Abbey-Mensah M, Driscoll JM, Blanc WA 1983 Pulmonary hypoplasia, a disorder on the rise? Pediatr Res 17:327A (abstr)

3. Perlman M, Williams J, Hirsch M 1976 Neonatal pulmonary hypoplasia after prolonged leakage of amniotic fluid. Arch Dis Child 51:349-353

4. Askenazi SS, Perlman M 1979 Pulmonary hypoplasia: lung weight and radial alveolar count as criteria of diagnosis. Arch Dis Child 54:614-618

5. Wigglesworth JS, Desai R 1981 Use of DNA estimation for growth assessment in normal and hypoplastic fetal lungs. Arch Dis Child 56:601-605

6. Goldstein JD, Reid LM 1980 Pulmonary hypoplasia resulting from phrenic nerve agenesis and diaphragmatic amyoplasia. J Pediatr 97:282-287

7. Kitagawa M, Hislop A, Boyden EA, Reid L 1971 Lung hypoplasia in congenital diaphragmatic hernia. A quantitative study of airway, artery and alveolar development. Br J Surg 58:342-346

8. Chamberlain D, Hislop A, Hey E, Reid L 1977 Pulmonary hypoplasia in babies with severe rhesus isoimmunisation: a quantitative study. $\mathrm{J}$ Pathol 43-52

9. Hislop A, Hey E, Reid L 1979 The lungs in congenital bilateral renal agenesis and dysplasia. Arch Dis Child 54:32-38

10. Blanc WA, Apperson JW, McNally J 1962 Pathology of the newborn and of the placenta in oligohydramnios. Bull Sloane Hosp Wom 8:51-64

11. Potter EL 1946 Bilateral renal agenesis. J Pediatr 29:68-76

12. Bain AD, Smith II, Gould IK 1964 Newborn after prolonged leakage of liquor amnii. Br Med J 598-99

13. Areechon N, Reid L 1963 Hypoplasia of lung with congenital diaphragmatic hernia. Br Med J 1:230-233

14. Finegold MJ, Katzew H, Genieser NB, Becker MH 1971 Lung structure in thoracic dystrophy. Am J Dis Child 122:153-159

15. Barr M, Burdi AR 1975 Spontaneous pleural effusion in human fetus. Teratology 11:139-141

16. Davies G, Reid L 1971 Effect of scoliosis on growth of alveoli and pulmonary arteries and on right ventricle. Arch Dis Child 46:623-632

17. Balcom RJ, Hakanson DO, Werner A, Gordon L 1985 Massive thymic hyperplasia in an infant with Beckwith-Wiedemann syndrome. Arch Pathol Lab Med 109:153-155

18. Naeye RL, Blanc WA 1972 Fetal renal structure and the genesis of amniotic fluid disorders. Am J Pathol 67:95-108

19. Blackburn WR, Bastin TR, Cooley NR, McCloud NA 1980 Etiological considerations of pulmonary hypoplasia in the newborn. Teratology $21: 28 \mathrm{~A}$

20. Cunningham M, Stocks J 1978 Werdnig-Hoffman disease. The effect of intrauterine onset on lung growth. Arch Dis Child 53:921-925
21. Vilos GA, McLeod WJ, Carmicheal L, Probert C, Harding PGR 1984 Absence or impaired response of fetal breathing to intravenous glucose is associated with pulmonary hypoplasia in congenital myotonic dystrophy. Am J Obstet Gynecol 148:558-562

22. Nimrod C, Varela-Gittings F, Machin G, Campbell D, Wesenberg R 1984 The effect of very prolonged membrane rupture on fetal development. Am J Obstet Gynecol 148:540-543

23. Moessinger AC, Blanc WA, Bassi JA, Collins MH, Kleinerman J, James LS 1983 Short term oligohydramnios (OA) and fetal lung growth. Pediatr Res 17:383A(abstr)

24. Moessinger AC, Collins MH, Blanc WA, Rey HR, James LS 1986 Oligohydramnios-induced lung hypoplasia: the influence of timing and duration in gestation. Pediatr Res 20:951-954

25. Hislop A, Fairweather DVI, Blackwell RJ, Howard S 1984 The effects of amniocentesis and drainage of amniotic fluid on lung development in macaca fascicularis. Br J Obstet Gynaecol 91:835-842

26. Ito S, Karnovsky MJ 1968 Formaldehyde-gluteraldehyde fixatives containing trinitro compounds. J Cell Biol 39:168a-169a(abstr)

27. Puchtler H, Meloan SN, Pollard GR 1976 Light microscopic distinction between elastin, pseudo-elastica (type III collagen?) and interstitial collagen. Histochemistry 49:1-14

28. Dunnill MS 1962 Quantitative methods in the study of pulmonary pathology. Thorax 17:320-328

29. Niewoehner DE, Kleinerman J 1977 Morphometric study of elastic fibers in normal and emphysematous human lungs. Am Rev Respir Dis 115:15-21

30. Collins MH, Kleinerman J, Moessinger AC, Collins AM, James LS, Blanc WA 1985 Morphometric analysis of the growth of the normal fetal guinea pig lung. Anat Rec (in press)

31. Draper RL 1920 The prenatal growth of the guinea pig. Anat Rec 18:369-392

32. Burri PH 1974 The postnatal growth of the rat lung. III. Morphology. Anat Rec 180:77-98

33. Vaccaro C, Brody JS 1978 Ultrastructure of developing alveoli. I. The role of the interstitial fibroblast. Anat Rec 192:467-480

34. Collins MH, Moessinger AC, Kleinerman J, Bassi J, Rosso P, Collins AM, James LS, Blanc WA 1985 Fetal lung hypoplasia associated with maternal smoking: a morphometric analysis. Pediatr Res 19:408-412

35. Moessinger AC, Fewell JE, Stark RI, Collins MH, Daniel SS, Singh M, Blanc WA, Kleinerman J, James LS 1984 Lung hypoplasia and breathing movements following oligohydramnios in fetal lambs. In: Physiological Development of the Fetus and Newborn. Academic Press, London, pp 293-298

36. Nakayama DK, Glick PL, Harrison MR, Villa RL, Noall R 1983 Experimental pulmonary hypoplasia due to oligohydramnios and its reversal by relieving thoracic compression. J Pediatr Surg 18:347-353

37. Kitterman JA 1984 Fetal lung development. J Dev Physiol 6;67-82

38. Alcorn D, Adamson TM, Lambert TF, Maloney JE, Ritchie BC, Robinson PM 1977 Morphological effects of chronic tracheal ligation and drainage in the fetal lamb lung. J Anat 123:649-660

39. Fewell JE, Johnson P 1983 Upper airway dynamics during breathing and during apnoea in fetal lambs. J Physiol 339:495-504

40. Thomas IT, Smith DW 1974 Oligohydramnios, cause of the nonrenal features of Potter's syndrome; including pulmonary hypoplasia. J Pediatr 84:811814 